\title{
A COMPLEMENTARY USE OF INFORMATION FROM SPACE-BASED DINSAR AND FIELD MEASURING SYSTEMS FOR OPERATIONAL MONITORING PURPOSES IN OPEN PIT IRON MINES OF CARAJÁS MINING COMPLEX (BRAZILIAN AMAZON REGION)
}

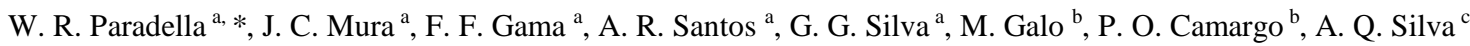 \\ ${ }^{a}$ National Institute for Space Research (INPE), São José dos Campos, São Paulo, Brazil - \\ waldir@1tid.inpe.br, mura@dpi.inpe.br, fabio@dpi.inpe.br, athos@ltid.inpe.br,gsilva@dsr.inpe.br \\ ${ }^{\text {b }}$ ão Paulo State University (FCT/UNESP), Presidente Prudente, São Paulo, Brazil - galo@ fct.unesp.br, paulo@ fct.unesp.br \\ ${ }^{\mathrm{c}}$ Federal University of Pará (IG/UFPA), Belém, Brazil - arnaldoq@ufpa.br
}

\section{ENGY-P ENGY-POSTERS}

KEY WORDS: rock slope monitoring, open pit iron mine, Carajás Province, DInSAR Time-Series, PSI, TerraSAR-X, total station/prisms, ground-based radar

\begin{abstract}
:
Now spanning five simultaneous open-pit operations with exploration carried out through open pit benching, Carajás complex encompasses the world's largest iron reserves. Open pit mining operations in the area can lead to slope instabilities with risks to personnel, equipment and production due to intense excavations in rock products of low geomechanical quality, blasting practices and heavy precipitation. Thus, an effective prediction and management of surface deformations should be a key concern for the mining operations. The ground displacement monitoring techniques in Carajás include surface measurement techniques at discrete points (total station/reflective prisms) and over area using SSR (Slope Stability Radar, a ground based radar). On the other hand, DInSAR techniques are receiving relevance in the mining industry for reasons such a synoptic and continuous coverage without the need for ground instrumentation and a point-to-point good accuracy of measuring displacements (millimeter to centimeter scale) over a dense grid. Using a stack of 33 StripMap TerraSAR-X images acquired over Carajás covering the time span from March 2012 to April 2013, a monitoring approach is discussed based on the complementary use of information provided by DInSAR (DInSAR Time-Series and Persistent Scatterer Interferometry) and surface measuring techniques (total station/prisms, ground-based radar).
\end{abstract}

\section{INTRODUCTION}

\subsection{Context}

The Amazon region is rich in mineral deposits of primary origin, which were concentrated to economic grades by weathering processes with a loss of silica and a residual/supergene enrichment of Fe (Vasconcelos et al., 1994). The Carajás Mineral Province (CMP), located in the easternmost border of Brazilian Amazon region, encompasses known iron reserves of the order of 18 billion tons with an average grade of $65.4 \%$ Fe content. Fully owned by Vale S. A. mining company, the world's largest iron ore producer, the exploration in Carajás is carried out through state of the art open pit benching with all operations computer guided from high technology control room.

Instabilities can be expected at any mining activity. Rock mass movements and surface deformations potentially can lead to slope instabilities or wall failures due to regular open pit mining operations. The eventual collapse of slopes can cause risk to personnel, equipment and mining infrastructures, disrupting mine scheduling with an increase in production cost. This scenario in Carajás gets worse over time due to intense deep excavations in rock products of very low geomechanical quality, coupled with blasting practices and heavy precipitation of the moist tropics, with deleterious effects on the overall stability. As a consequence, the iron mines of the Carajás Complex have presented slope failure and collapse events. Thus, an effective prediction and management of mining induced deformations of ground surface should be a key concern for operations in the area.

A classification scheme of the available monitoring systems for open pit mines was recently presented (Vaziri et al., 2010). In this scheme, ground movement measurement techniques were divided into surface measurements at discrete points with specific instruments (total stations/reflecting prisms, extensometers, etc.), and surface measurements over areas based on scanning techniques, such as ground based radar, LASER and image-based techniques. It is important to consider that systems that monitor displacements over large areas yield more information when compared to systems designed for monitoring individual points, since the former can provide data about the spatial pattern of deformations. Thus, a system like a groundbased radar, which monitors deformation quasi-continuously, is considered "a real-time technique" and is widely used by open pit mines for operational safety (production-critical monitoring). Lower cost monitoring methods such as total

\footnotetext{
* Corresponding author. This is useful to know for communication with the appropriate person in cases with more than one author.
} 
station/prism based survey networks and extensometers are normally used for primary monitoring of wall areas. When instability is detected and if the area is not covered by prisms, they are deployed. On the other hand, if prisms are available a denser grid is normally used. In both situations, a simultaneous monitoring based on ground-based radar is implemented.

Taking into account that large open-cut mining encompasses significant areas of extent with a great demand of ground movement information, within and beyond the pit limits (including stock and waste piles, tailings ponds, dams, transport routes, processing facilities, infrastructure, etc.), the use of Differential Interferometric Synthetic Aperture Radar (DInSAR) for monitoring purpose is justified, particularly due to the versatility of systematic all-weather data acquisition through satellite SAR systems. The basic advantages of DInSAR techniques over total station/reflecting prisms or ground-based radar techniques are that measurements of displacements can be made without fieldwork and terrain instruments, and detailed motion information (milimeter to centimeter scale) can be acquired over large areas, rather than point locations or sectors. In this study, we discuss aspects of the complementary usage of space-based DInSAR techniques (DInSAR Time-Series, Persistent Scatterer Interferometry) based on TerraSAR-X data with geotechnical field measuring techniques (total station/reflecting prisms, ground based radar), which proved to be fundamental for mapping ground displacements within and around the large open pit iron mining complex of Carajás.

\subsection{Test-site characteristics}

The Carajás Mineral province, with an area of 120,000 square kilometers, is marked by mountainous terrains, characterized by a set of hills and plateaus surrounded by southern and northern lowlands, deep chemical weathering which produces thick oxisols (latosols), totally covered by Ombrophilous Equatorial forest communities (Paradella et al., 1994). A remarkable structural feature in the region is an open regional synclinorium, about $200 \mathrm{~km}$ long and some $40 \mathrm{~km}$ wide, aligned eastsoutheast. Outcrop areas of the banded iron formation form high, normally bare, laterite-capped plateaus named clearings, which stand above the adjacent equatorial forest, deeply weathered and dissected terrain. The northern limb of the synclinorium is marked by an irregular line of nine plateaus (collectively called Serra Norte), while the southern limb forms another such line (Serra Sul). The deposits are covered by thick, lateritic duricrusts developed over volcanic rocks and ironstones. The mining activities on Serra Norte are related to two iron orebodies (N4 and N5) and were started by 1984 with the N4E mine. Now spanning five simultaneous open-pit mine operations (figure 1), the Carajás Mining Complex has produced approximately 300,000 metric tons of iron ore per day.

The ore deposits are related to metavolcanic and metasedimentary rocks of the Grão-Para Group subdivided into two main units: the volcanic rocks of the Parauapebas Formation (Meireles et al., 1984) and the ironstones of the Carajás Formation (Beisiegel et al., 1973). In the region, units of the Parauapebas Formation are tectonically juxtaposed above and below the Carajás Formation. The ironstones of the Carajás Formation are represented by jaspilites and iron ores, intruded by dikes and mafic sills. All the rocks were affected by very low metamorphic grade (greenschist facies). Jaspelite comprises alternating layers of crystalline quartz and/or chert bands, with hematite, martite, magnetite and pyrite. Iron ore is composed of interlayered hematite and silica, which are distinguished based on their hardness, e.g. "soft" hematite, "hard" hematite, etc. The most voluminous ore consists of soft hematite ore with lenses of hard ore, and is considered a product of progressive weathering and $\mathrm{SiO} 2$ leaching (Tolbert et al., 1971).

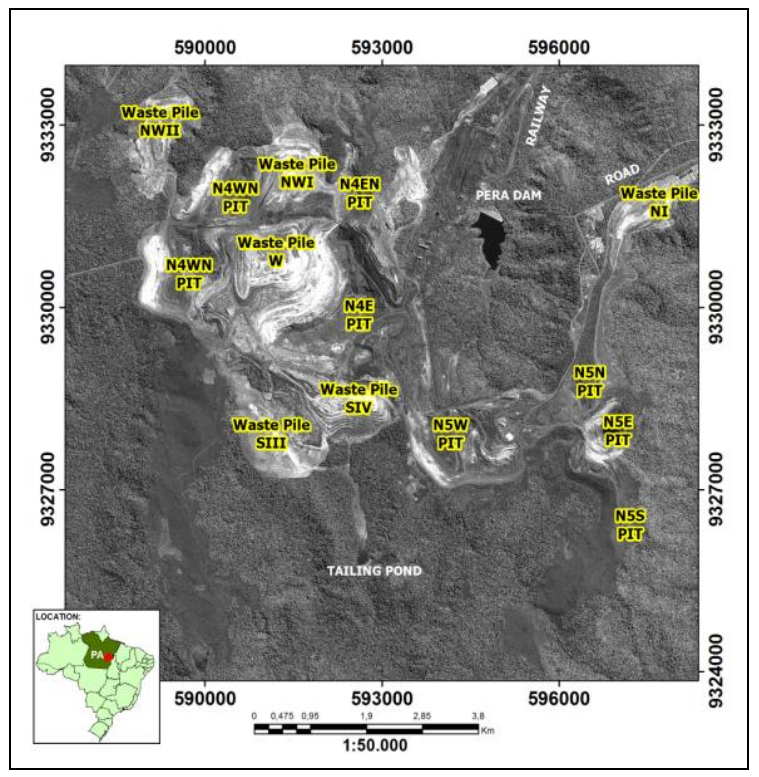

Figure 1. Location of Carajás iron complex in the Brazilian Amazon region (Pará State), showing the open pits, waste piles and related mining infrastructures.

A detailed account of the geological and geomechanical information for open-cast pits in Carajás was available for the investigation. Surface outcrop geological mapping and geomechanical rock classification were carried at detailed scale (BVP 2011 a, b, c). Geomechanical parametrizations and strength tests for rocks units and back analysis of slope failures were also performed (Sá 2010). According to these data, the dominant rock masses showed a very low geomechanical quality based on RMR (Rock Mass Rating) parameter classification) ranging from RMR V and IV, while fair to very good rocks masses (RMR II and III) are mapped as isolated bodies. A history of instabilities in the N4E and N5W mines has been compiled for the period of the investigation (Vale 2012 a, b, Vale 2013). The events showed a variation of intensity ranging from small surface movements, settlements, presence of tension cracks, rockfalls, failures and even collapses (table 1).

\subsection{Current geotechnical monitoring systems in Carajás}

The slope monitoring approach in Carajás includes visual inspections to detect the onset of instability, instruments measuring surface (total station/reflecting prisms and ground based radar) and subsurface displacements (piezometers, extensometers). Total station (Trimble S6 and S8) and reflecting prisms distributed at a relatively wide spacing around the slopes are the primary method for monitoring. They provide a very cost-effective way of measuring $3 \mathrm{D}$ displacements. If an unstable condition is anticipated or a movement is detected, the use of the ground-based radar is required. 


\begin{tabular}{|c|c|c|}
\hline Event & Location & $\begin{array}{c}\text { Main } \\
\text { Characteristics } \\
\end{array}$ \\
\hline $\begin{array}{c}\text { Out } 17 \text { - Nov } 01 \\
2012\end{array}$ & $\begin{array}{l}\text { N5W mine } \\
\text { (SW flank) }\end{array}$ & $\begin{array}{l}\text { Fractures (bench } \\
\text { faces) and tension } \\
\text { cracks (berms, } \\
\text { ramps). Maximum } \\
\text { deformation } \\
\text { measured by SSR } \\
\text { was } 16.9 \mathrm{~mm} \text {. }\end{array}$ \\
\hline $\begin{array}{c}\text { Aug 27- Sept } 04 \\
2012\end{array}$ & $\begin{array}{c}\text { N4E } \\
\text { (W flank) }\end{array}$ & $\begin{array}{l}\text { Tension cracks, } \\
\text { settlements, small } \\
\text { ruptures, rockfalls. } \\
\text { Maximum } \\
\text { deformation } \\
\text { measured by SSR } \\
\text { was } 3272 \mathrm{~mm} \text {. }\end{array}$ \\
\hline $\begin{array}{c}\text { Feb 27-Mar } 11 \\
2013\end{array}$ & $\begin{array}{c}\text { N4E } \\
\text { (NNE flank) }\end{array}$ & $\begin{array}{l}\text { Fractures on the } \\
\text { surface, slope } \\
\text { collapses, talus } \\
\text { mass motions. } \\
\text { Accumulated } \\
\text { deformation } \\
\text { measured by SSR } \\
\text { was } 1103.14 \mathrm{~mm} \text {. }\end{array}$ \\
\hline
\end{tabular}

Table 1. Slope instabilities events in the area (sources: Vale 2012 a, b, Vale 2013)

However, the use of prisms presented limitations in the area given by (1) raw data normally noisy, (2) visibility is needed among station and measured points, and environmental conditions (presence of haze, dust, intense precipitation) restrict systematic measurements, (3) access to unstable areas is normally complicated for installing prisms, (4) results are not available in real time, and (5) it is not feasible to monitor the whole mining complex. Ground-based radar has the advantage that a section of a wall or a sector of the pit can be monitored automatically and remotely in near-real time without the use of reflectors and independent of atmospheric conditions.

The ground-based radar SSR (Slope Stability Radar, GroundProbe Company) uses a phase measurement taken on bench walls, similarly to the interferometry technique, to infer small changes in range associated with pre-cursor movements to mine slope failures. These small changes in phase are accumulated over time for each subsequent scan and converted to displacement values. SSR features a 1.80 m-diameter scanning parabolic dish antenna, mounts, controlling/datacollecting computer, remote area power supply, warning siren and lights, CCD camera, communication links, and Internet compatibility. The system uses real aperture radar to scan a slope both vertically (height) and horizontally (azimuth) with a scanning at a rate of $100 / \mathrm{sec}$ over a range of \pm 600 vertically and 2700 horizontally. Typical scan repeat time is $15 \mathrm{~min}$. Line-ofSight (LoS) displacement can be measured to $\pm 0.2 \mathrm{~mm}$ without the use of reflectors. However, even though a ground-based radar has the ability to cover a broad area, the monitoring is still restricted to sectors of the pit. Mining operations generally have variable geotechnical conditions and distinct failure mechanisms. In large open-pit mines such as in Carajás, it is essential to use multiple monitoring systems to ensure a balanced slope risk strategy.

\section{REMOTELY SENSED DATA}

A stack of 33 Strip Map TerraSAR-X (TSX-1) images, with repeat cycle of 11 days, was used for the investigation covering the period of March 20, 2012 to April 20, 2013. The Single Look Complex images were acquired under ascending passes (look azimuth $=78$ degrees), incidence angle range of 39.89 42.21, spatial resolution of $1.7 \mathrm{~m} \times 3.49 \mathrm{~m} \mathrm{(} \mathrm{g} \mathrm{x} \mathrm{az}$ ), pixel spacing of $1.36 \times 1.90 \mathrm{~m}$ ( $\mathrm{rg} \mathrm{x} \mathrm{az})$, and width swath of $30 \mathrm{~km}$. In order to minimize the topography phase error in the interferometric process, a high resolution DEM was generated based on a panchromatic GeoEye-1 stereo pair. The GeoEye stereo images were acquired on July 1st, 2012. The images were provided with $0.5 \mathrm{~m}$ spatial resolution and RPCs (Rational polynomial coefficients). The generation of the DEM was based on OrthoEngine PCI Geomatics through the Rational Function Method (RFM) as the geometric model. The panchromatic DEM was produced at $2 \mathrm{~m}$ spacing using, and its elevation values compared to seven well-defined accurate vertical check points have provided RMS and maximum errors of $1.2 \mathrm{~m}$ and 1.6m, respectively (Paradella and Cheng, 2013).

\section{METHODOLOGICAL APPROACH}

\subsection{DInSAR Time-Series}

Algorithms for DInSAR Time-Series (DInSAR TS) analysis have been developed to better address the conventional DInSAR pairs limitations, by using a redundant number of differential interferograms with potential to determine spatially and temporally ground displacement, where the desirable deformation information can be separated from topography error, atmospheric delay and noise (Hopper et al., 2012). In this study, the time-series deformation was retrieved by using an extension of the Singular Value Decomposition with a set of additional weighted constrain on the acceleration of the displacement to control the smoothness of the time-series solutions. Temporal smoothing was enhanced using a finite difference approximation constraint, assuming less deformation to occur during short period of time. Thus, by including a smoothing constraint, atmospheric artefacts will be minimized depending on how strongly temporal smoothing is applied. The smoothing constraint and the height error related term were incorporated into the inversion of the system that relates the observed unwrapped interferograms phase with the average displacement velocity.

The time-series solution used in this study (Strozzi et al., 2001) was implemented in the SAR and Interferometric package by GAMMA Remote Sensing and Consulting AG (GAMMA). The application of the DInSAR time-series using the 33 TSX images was firstly based on a test of coherence of the interferograms according to the time interval between interferometric pair. This test was carried out in order to select the maximum time interval for construction of the pairs. All interferograms were obtained by using a complex multi-look operation, with 2 looks in range and azimuth, resulting in a pixel dimension of about 2.6 and 3.8 $\mathrm{m}$ in range and azimuth, respectively. Adaptive spectral filter with window size equals to 32 by 32 was applied on the interferograms to produce interferometric coherence images. Regions with coherence less than 0.3 have been masked out. The phase unwrapping process was performed using the algorithm MCF (Constantini, 1998). Details of this subject with an example of application in Carajás were already presented (Mura et al., 2014). 


\subsection{Persistent Scatterer Interferometry (PSI)}

The PSI technique used in this study relies on identifying pixels whose scattering properties vary little with time and look angle in a stack of co-registrated SLC images. The purpose of PSI is to analyze the temporal and spatial characteristics of the interferometric phase of individual point target or PS (Persistent Scatterer). These point targets are coherent even for the interferometric pairs with long spatial baselines and remain stable over long time periods to permit analysis of the phase history (Ferretti at al., 2001). PSI analysis was carried out using the IPTA (Interferometric Point Target Analysis) software, which is the implementation of PSI by GAMMA Remote Sensing and Consulting AG (Werner et al. 2003).

The IPTA software is a toolbox that can support many different methodologies including different alternatives for scatterers candidate selection, spatial and temporal phase unwrapping, and supporting approaches for single as well as multireference stacks (Wegmuller et al., 2010). PSI provides better accuracy than that of DInSAR TS. The former can enhance the model and diminish the effect of the atmospheric phase, which is related to the path delay heterogeneity during the acquisitions times, whereas the latter can detect larger deformation rates and provides a more homogeneous and extensive information related to the ground deformation, but at the cost of a loss in spatial resolution.

\section{RESULTS}

\subsection{DInSAR Time-Series}

A deformation map (figure 2) covering the Carajás complex was obtained using the data stack of 33 TSX-1 scenes covering the time span from March 2012 to April 2013 (dry and wet seasons) with a configuration of 31 interferometric pairs selected based on the highest mean coherence. Relevant ground deformations were provided related to the overall stability around and within pits, waste piles and mining infrastructures (green-bluish regions). However, high deformation rates (yellow-reddish regions) with negative values corresponding to motion away from the satellite $(\mathrm{mm} / \mathrm{yr})$ were also detected over the waste piles NW-1 (letters A), W (letter B) and SIV (letter C). Furthermore, it was also possible to detect evidences of deformation over cut slopes of the N5W mine (letter D). The maximum accumulated displacements were $\sim-121 \mathrm{~cm}$ (waste pile NW-1), $\sim-79 \mathrm{~cm}$ (waste pile $\mathrm{W}$ ), $\sim-48 \mathrm{~cm}$ (waste pile $\mathrm{S}$ IV), and $-35 \mathrm{~cm}$ (cut slopes of $\mathrm{N} 5 \mathrm{~W}$ ).
For the waste piles, the detected deformation was interpreted as related to settlements, showing values normally expected for this manmade structure. On the other hand, lithostructural and lithogeomechanical attributes have played a key role in the displacements related to cut slopes. Since DInSAR TS is based on a multi-look (not a full resolution) processing, it is not a suitable technique for accurate displacement measurements ( $\mathrm{mm}$ scale). However, it is still useful in identifying footprints of progressing movement, including non-linear and fast deformation components, providing a synoptic view of the spatial displacement distribution, particularly when an insufficient number of SAR images are available over an area of interest to perform a full PSI analysis.

\subsection{PSI}

The IPTA processing was performed with the first 19 TSX-1 scenes covering the dry season in the area. Figure 3A shows spatial distribution of PS detected for N4E mine (small dots). LoS average deformation annual velocities (mm/year) of PSs are color-coded from blue-greenish (stable conditions) to red (a movement away from the sensor, typically corresponding to subsidence). Large dots indicated the field locations of reflecting prisms, which were deployed on bench faces along the eastern and southern flanks of N4E mine. PSI provided PSs with precision ( $\mathrm{mm} \mathrm{scale)}$ and higher spatial density as compared to prim measurements, exploiting both point-wise and distributed radar scatterers available within the area of interest.

The PS, with the highest accumulated deformation for the period $(\sim-23.9 \mathrm{~cm})$ and the highest deformation rate $(\sim-46.9$ $\mathrm{cm} /$ year) corresponding to LoS range lengthening, was measured over the waste pile W. This displacement was interpreted as related to settlement phenomena. The same trend was detected for cut slopes of central flank sector of the N4E mine (highest accumulated deformation $\sim-10.8 \mathrm{~cm}$, deformation rate $\sim-21.8 \mathrm{~cm} /$ year). This subsidence was attributed to accommodation of weathered metavolcanic rocks coupled with controlled blasting activities to improve the excavation performance. The time-series deformation profiles for these two PSs are presented in figures 3B and 3C. 


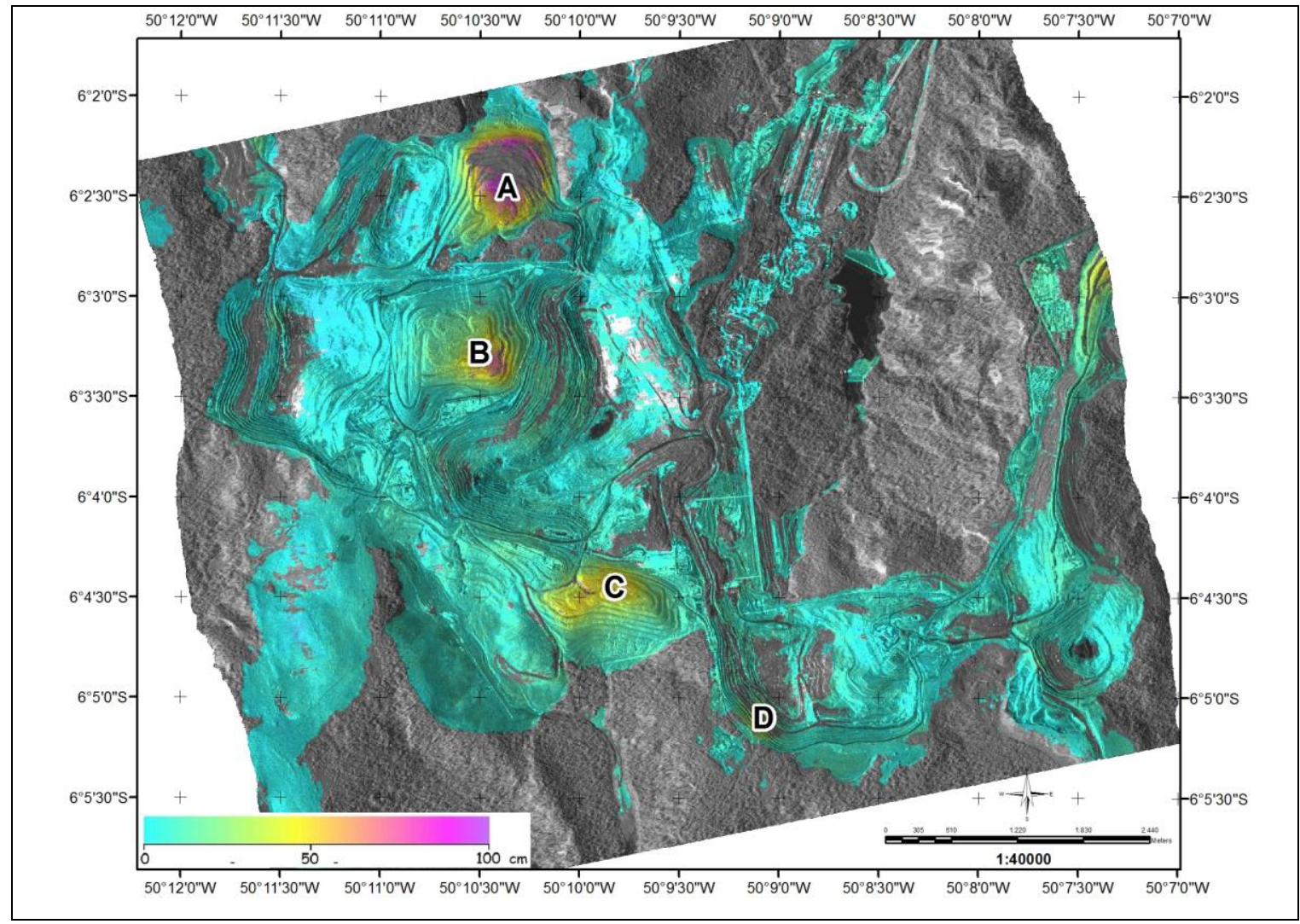

Figure 2. DInSAR TS deformation map, expressed by the average LoS velocity using the 33 TSX-1 images on the panchromatic GeoEye image, providing a synoptic view of the deformation affecting the Carajás complex (letters discussed in the text).
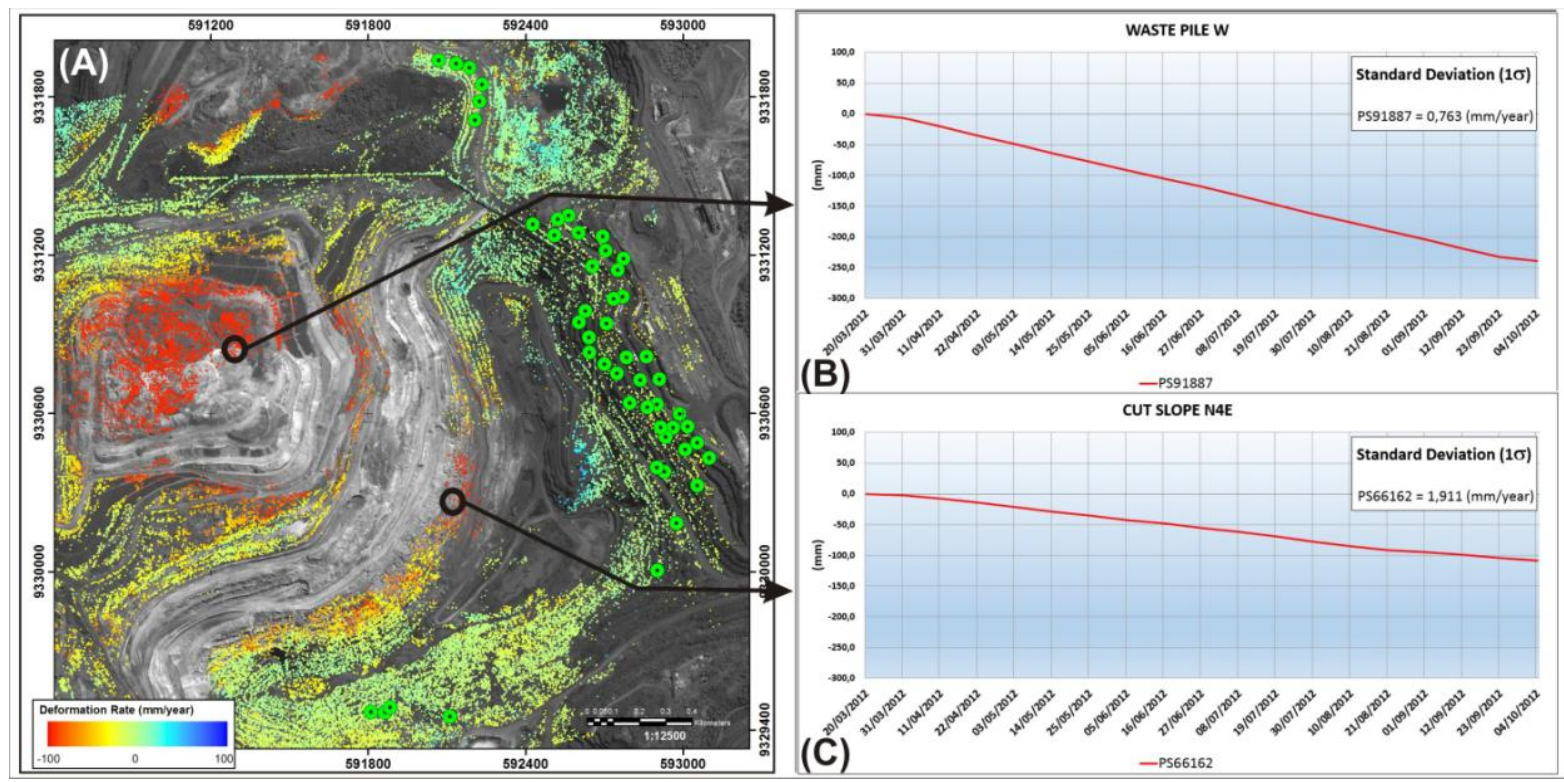

Figure 3. (A) Spatial distribution of PSs (IPTA) using the first 19 TSX-1 images for N4E mine, visualized by the average LoS velocity (mm/year) on the panchromatic GeoEye image. Large green circles show the location of prisms. Areas without PS are indicative of low coherence due to rapidly changed surfaces, (B) TSX-1 deformation profile related of a PS located over the waste pile W, (C) TSX-1 deformation profile of a PS located on a cut slope in the central flank of the pit of N4E mine.

\subsection{Reflecting prisms and ground-based radar}

The number of prisms to be used in the monitoring of an open pit depends on several factors (size of the pit, history of instabilities, access, anticipate size of failures, characteristics of suspected unstable zone, etc.). If a movement is detected or specific unstable conditions are anticipated, a more extensive surveying program with a denser prisms array may be necessary. 
Furthermore, the frequency of measurements also depends on the geologic and geotechnical nature of the sector of the pit addressed, operations around the slope, objectives of the monitoring programme in place. For slow-moving slopes, the measurements may be carried out every week or monthly basis. For a potentially rapidly-moving slope, more frequent readings at pre-set intervals are implemented. However, manual total station observations are very time consuming, labour intensive and have the potential for human error when recording survey data.

In figure 4, the LoS projected deformation of an IPTA PS (PS \# 148757) and the corresponding prism time series (prim \#3) for a cut slope in the N4E mine are superimposed. The PS was located $13 \mathrm{~m}$ from the prism, and the prism vertical values $(\Delta \mathrm{h})$ were projected along the satellite LoS by multiplying these values by the cosine of the incidence angle $\left(\Theta=41.3^{0}\right)$. The data covered a three-months period (June 22 - Sept 29/2012), showing a much higher temporal frequency of prism measurements ( 3 a 4 days) as compared to the PS (11 days). Prims measurements have exhibited a higher dispersion of values due to adverse weather conditions (dust and haze during dry season impair the visibility among station and prisms), the use of manual total station observations with potential human errors, distinct operator teams, etc. However, both sources of independent measurements showed an overall agreement, and it was possible to conclude for an overall stability of the cut slope. The possibility of a more frequent monitoring favours the usage of prisms as an important tool to ensure safety and predicting the stability of structures and slopes for early warning signs.

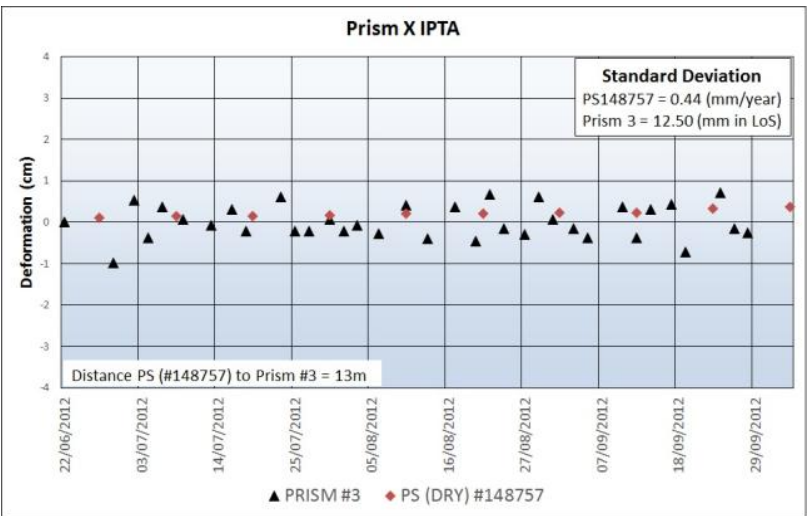

Figure 4. Time-series deformation profiles for a reflecting prism and corresponding PS (IPTA) for a cut slope (N4E mine) during a period of three months.

As presented in table 1, important slope instability events occurred in the cut slopes of NNE flank (cava central area) of N4E mine during the period of Feb 27- March 11/2013, expressed by progressive deformations with fractures on bench walls, tension cracks and settlements on berms, collapses of slopes, and rockfalls (talus mass movements over various benches). Based on Vale's report, geological structures played a key role in controlling the displacements, which were monitored by SSR (figure 5). Unfortunately, no prism measurements were available for this period, but due to rockfalls, it would impossible the analysis of instability with this technique. Furthermore, with failures of the TSX acquisitions in the period, it was not also possible to remotely track these slope ruptures. This example highlighted the importance of SSR as a "real time technique", providing effective risk management of wall control due to unexpected rockfalls with sufficient warning for production to act. SSR has the advantage that the sector of the pit could be monitored automatically and remotely without the use of reflectors and independent of atmospheric conditions. Based on previous discussions, table 1 shows the main attributes of each monitoring techniques addressed in the paper.

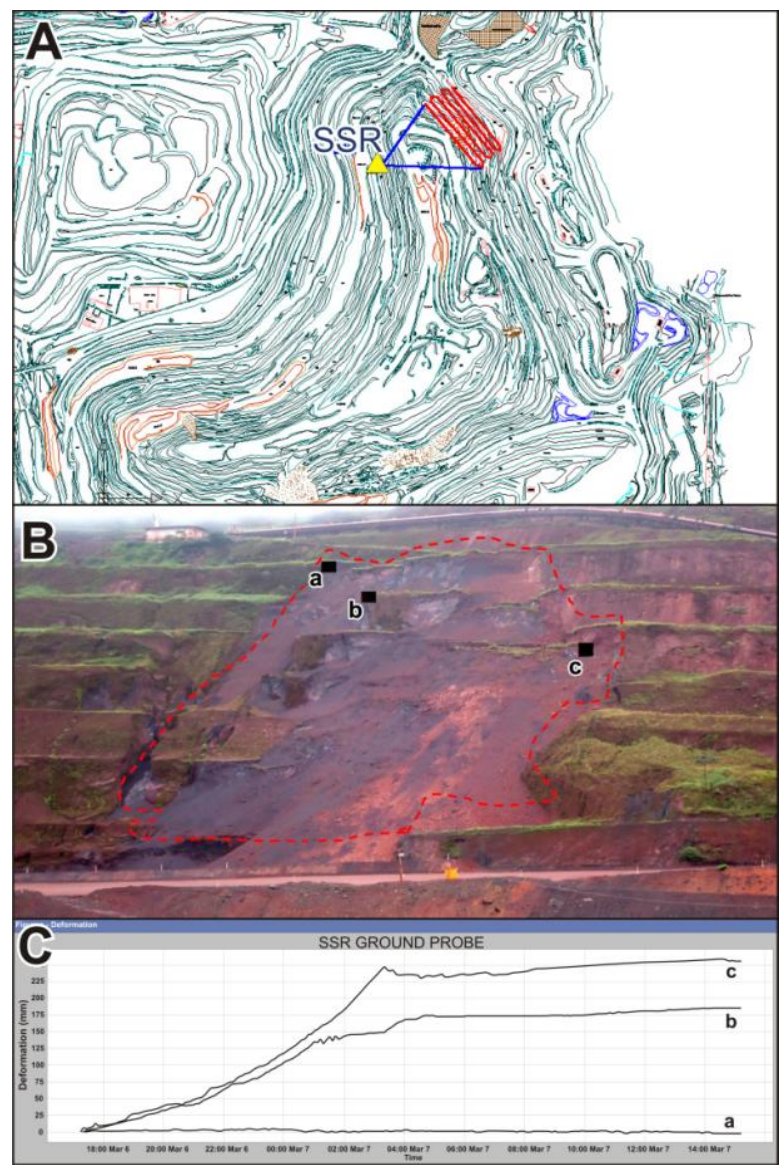

Figure 5. (A) SSR configuration used for monitoring cut slopes in the NNE flank of N4E mine. (B) Field picture showing rockfalls and location of specific points measured by SSR on bench walls (letters a, b, c). (C) SSR deformation profiles related to points $\mathrm{a}, \mathrm{b}, \mathrm{c}$.

\begin{tabular}{|c|c|c|c|}
\hline Technique & $\begin{array}{c}\text { Ground based } \\
\text { radar }\end{array}$ & Total station/ Prism & $\begin{array}{c}\text { DinSAR Time- } \\
\text { Series , PSI }\end{array}$ \\
\hline $\begin{array}{c}\text { Measurement } \\
\text { accuracy }\end{array}$ & $\begin{array}{c}\text { Excellent }(\mathrm{mm}) \text { in } \\
\text { the LoS }\end{array}$ & $\begin{array}{c}\text { Excellent }(\mathrm{mm} / \mathrm{cm}) \\
\text { in X, Y, }\end{array}$ & $\begin{array}{c}\text { Synoptic (cm) and } \\
\text { detail (mm) of } \\
\text { several "targets" }\end{array}$ \\
\hline $\begin{array}{c}\text { Temporal } \\
\text { resolution }\end{array}$ & $\begin{array}{c}\text { Excellent (real time } \\
\text { and continuo) }\end{array}$ & $\begin{array}{c}\text { Excellent (can be } \\
\text { daily) }\end{array}$ & $\begin{array}{c}\text { Low } \\
\text { Current: 8 days } \\
\text { (Cosmo-Skymed) } \\
\text { and 11 days (TSX- } \\
1) \text { in the area. }\end{array}$ \\
\hline $\begin{array}{c}\text { Real time } \\
\text { Technique } \\
\text { (warning) }\end{array}$ & Excellent & Good & Inappropriate \\
\hline $\begin{array}{c}\text { Monitoring for } \\
\text { planning }\end{array}$ & inappropriate & $\begin{array}{c}\text { Fair with a dense } \\
\text { array }\end{array}$ & Excellent \\
\hline
\end{tabular}

Table 1. Attributes of displacement measurement techniques for the open pit iron mines of Carajás. 


\section{CONCLUSIONS}

The basic objective of any slope monitoring program should be to prevent failures, take remedial measures and provide solutions against instability. Mining operations generally have variable geotechnical conditions and related distinct failure mechanisms. In large open-pit mines such as in Carajás, it is essential to use multiple monitoring systems to ensure a balanced slope risk strategy. The investigation emphasized that the complementary and synergistic use of the three information systems (total station/prisms, ground-based radar, space-based DInSAR) are the best option for monitoring and predicting surface instabilities in order to optimize the mining operations. The potentiality of space-based DInSAR can be fully explored with the use of SAR scenes acquired in both ascending and descending passes in order to minimize lack of information due to radar foreshortening, to get redundancy in case of satellite acquisition failures and to derive vertical and horizontal deformation components.

\section{ACKNOWLEDGEMENTS}

This research was carried out under the scope of a FAPESPVale-INPE project (FAPESP Process no. 2010/51267-9). The authors would like to thank Vale S.A. for providing access to geological, geomechanical and field geotechnical data, and particularly to Aristotelina Silva and the Geotechnical Vale's team in Carajás for the support during field campaigns. The authors are also grateful to $\mathrm{CNPq}$ for a grant received by the first author.

\section{REFERENCES}

Beisiegel, V. R., Bemardelli, A. L., Drummond, N. F., Ruff, A.W., Tremaine, J.W., 1973. Geologia e recursos minerais da Serra dos Carajás. Brazilian Journal of Geosciences, 3, pp. 215-242.

BVP, 2011a .Lithostructural and lithogeomechanical mapping of N4E mine. Vale's internal report, 80 pgs.

BVP, 2011b . Lithostructural and Lithogeomechanical mapping of N5W Mine. Vale's internal report. 61 pgs.

BVP, 2011c. Lithostructural and Lithogeomechanical mapping of N4W Mine. Vale's internal report, 75 pgs.

Constantini, M., 1998. A Novel Phase-Unwrapping Algorithm based on Network Programming, IEEE Transactions on Geosciences and Remote Sensing., 36 (3), pp. 813-820.

Ferretti, A., Prati, C., Rocca, F., 2001. Permanent Scatterers in SAR Interferometry. IEEE Transactions on Geoscience and Remote Sensing, 39 (1), pp. 8-20.

Hopper, A., Bekaert, D., Spaans, K., Arikan, M., 2012. Recent advances in SAR Interferometry time series analysis for measuring crustal deformation. Tectonophysics, 514-517 (January), pp.1-13.

Meireles, E. M., Hirata, W.K., Amaral, A. F., Medeiros Filho, C.A., Gato, W. C. A., 1984. Geologia das Folhas Carajás e Rio
Verde, Província Mineral dos Carajás, Estado do Pará. Annals of the Brazilian Geological Congress, 31, pp. 2164-2174.

Mura, J.C., Paradella, W.R., Gama, F.F., Santos, A.R., Galo, M., Camargo, P.O., Silva, A.Q., Silva, G.G. 2014. Monitoring of surface deformation in open pit mine using DInSAR TimeSeries: a case study in the N5W iron mine (Carajás, Brazil) using TerraSAR-X data. Proc. of SPIE RS 2014, Vol. 9243, 924311-1, doi: 10.1117/12.2066886.

Paradella, W. R., Silva, M. F. F., Rosa, N. A., Kushigbor, C. A., 1994. A geobotanical approach to the tropical rain forest environment of the Carajás Mineral Province (Amazon region, Brazil), based on digital TM-Landsat and DEM data. International Journal of Remote Sensing, 15 (8), pp. 1633-1648.

Paradella, W.R., Cheng, P., 2013. Using Geoeye-1 stereo data in mining application: automatic DEM generation. Geoinformatics, 16 (January/February), pp.10-12.

Sá, G., 2010. Caracterização litoestrutural e parametrização geomecânica das superfícies de rupturas em taludes da Mina N4E, Carajás,Pa. Thesis for the Master Degree in Geotechnical Engineering, Federal University of Ouro Preto, 172 pgs.

Strozzi, T., Wegmuller, U., Tosi, L., Bitelli, G., Spreckels, V., 2001. Land Subsidence Monitoring with Differential SAR Interferometry. Photogrammetric Engineering \& Remote Sensing, November, pp. 1261-1270 .

Tolbert, G.E., Tremaine, J.W., Melcher, G. CA., Gomes. C.B.. 1971. The recently discovered Serra dos Carajás Iron Deposits, northern Brazil. Economic Geology and the Bulletin of the Society of Economic Geologist, 66 (7), pp. 985-644.

Vale S.A., 2012a. Geotechnical monitoring with Slope Stability Radar: SW Flank, N4E Mine. Internal Vale's report, GAGHN/GEDEN, September, 8 pgs.

Vale S.A., 2012b. Geotechnical monitoring with Slope Stability Radar: SW Flank, N5W Mine. Internal Vale's report, GAGHN/GEDEN, November, 4 pgs.

Vale S.A. 2013. Geotechnical monitoring with Slope Stability Radar: Central pit, N4E Mine. Internal Vale's report, GAGHN/GEDEN, March, 5 pgs.

Vasconcellos, P.M., Renne, P.R., Brimhall, G.H., Becker, T.A., 1994. Direct dating of weathering phenomena by ${ }^{40} \mathrm{Ar} /{ }^{39} \mathrm{Ar}$ and $\mathrm{K}-\mathrm{Ar}$ analysis of supergene K-Mn oxides. Geochimica et Cosmochimica Acta, 58 (6), pp. 1635-1655.

Vaziri, A., Moore, L., Ali, H., 2010. Monitoring systems for warning impending failures in slopes and open pit mines. Natural Hazards 55, pp. 510-512

Wegmuller, U., Walter, D., Spreckels, V., Werner, C.L., 2010. Nonuniform ground motion monitoring with TerraSAR-X Persistent Scatterer Interferometry, IEEE Transactions on Geoscience and Remote Sensing, 48 (2), pp. 897-904.

Werner, C., Wegmüller, U., Strozzi, T., Wiesmann, A., 2003. Interferometric point target analysis for deformation mapping. Proceedings IGARSS'03, Tolouse, pp. 4362-4364. 